\title{
Interactions between Elderly Adults and Preschool Children in a Horticultural Therapy Research Program
}

\author{
$M$ ary L. Predny ${ }^{1}$ and Diane Relf ${ }^{2}$
}

ADDITIONAL INDEX WORDS. intergenerational, activities, daycare, volunteers

SUMmARY. This report examines the behavior of elderly adults and preschool children during horticultural therapy (H T) activities to determine if combining intergenerational groups would complement or detract from the H T goals for each group separately. D uring a 10-week observation period, data were collected on video documenting attendance, participation time and pattern during separate age group and intergenerational activities. These data were used to determine if interactions changed over time or in response to different activities. Participation appeared to be affected by activity design, difficulty level, individual ability, and availability of assistance from volunteers. Children's participation during separate age group activities appeared to be affected mainly by the difficulty level and activity design. Elderly adults' participation during separate age group activities appeared to be affected by individual ability limitation and availability of assistance. Children's intergenerational participation scores appeared to show an increase in the category of "working with direct assistance", while elderly adults' intergenerational scores appeared to show an increase in the categories of "no participation" and "independent participation". In part, the change in intergenerational participation appeared to be due to a decrease in assistance available from volunteers for each individual. For some individuals, the introduction of intergenerational groups appeared to detract from personal participation in horticulture activities. If the goal of the HT is directly related to the individual's activity in horticulture (i.e., increased self-esteem from successfully designing and building a terrarium), the intergenerational element appears to reduce the potential for that benefit. The percentage of total social interaction time between the generations during activities increased over time. The intergenerational activities involving plant-based activities seemed to be more successful at increasing intergenerational exchange than the craft-type activities. Therefore, horticulture may be a useful activity for programs with a goal of increased intergenerational interaction.

\footnotetext{
he goal of this observational research was to discover if intergenerational activities would supplement or detract from horticulture therapy $(\mathrm{H}$ T) goals when compared to working with elderly adults or preschool children separately. I ntergenerational H T programs have been used to increase the opportunity for diverse social interactions in a horticulture program for special groups (Abbott et al., 1997; Epstein and Greenberger, 1990; Kerrigan and Stevenson, 1997). $\mathrm{H}$ owever, intergenerational $\mathrm{H} \mathrm{T}$ programs have not been widely used or studied, so the impacts of such programs are unknown.
}

\footnotetext{
The cost of publishing this paper was defrayed in part by the payment of page charges. U nder postal regulations, this paper therefore must be hereby marked advertisement solely to indicate this fact.

${ }^{1}$ G raduate student, H orticulture D epartment, Virginia Polytechnic Institute and State U niversity, Blacksburg, VA 24061-0327.

2Professor, D epartment of $\mathrm{H}$ orticulture, Virginia Polytechnic Institute and State U niversity, Blacksburg, VA 24061-0327.
} 
Intergenerational programs in general have been studied in various situations, but theresults areinconclusiveor contradictory ( $D$ ellman-J enkins et al., 1991; Seefeldt, 1989). It is important, therefore, to study these interactionsto determineif they are an asset to HT programming, and conversely, to see if horticulture is an appropriate activity for intergenerational programming.

Previous research indicates several guidelines that can lead to more successful intergenerational programming. These include making the contact beneficial for both groups rather than having one group serve the other (Tice, 1985), designing projects that "have a definite purpose or end product" (Aday et al., 1991), establishing programs that are long-term so the individuals have a chance to establish relationships with one another (Seefeldt, 1989), and ensuring that positive attitudes develop as a result of discovered similarities between the groups (Chapman and Neal, 1990). Seefeldt (1987) proposed recommendations for ensuring successful programs that reinforce these points and include "protecting the prestige of elders as well as children; limiting frustration for both adults and children by arranging for contact that is intimate, not casual; planning for interaction that has integrity and is functional for both groups; and ensuring that contact between old and young is rewarding and pleasant for both groups."

According to theseguidelines, $\mathrm{HT}$ has excellent potential as a focus for intergenerational programs because it provides benefits for all persons involved, a definite end product to share and discuss, a long-term project with intrinsic rewards, and acommon interest in order to establish a connection between the groups. The horticultural activitiescould also beadapted to meet the needs of both groups involved. However, it is not as certain that intergenerational programs would complement a H T program. For example, the specific goals of gardening with elderly adults and gardening with children have some different objectives that may make the combination of the two groups inappropriate.

The needs of elderly adults and children that are addressed by $\mathrm{HT}$ have many similarities including increased autonomy, a sense of wonder and excitement, physical and mental stimulation, social interactions, sensory stimulation, and creative expression (Bunn, 1986; Green, 1994; $\mathrm{H}$ aas et al., 1998; $\mathrm{H}$ efley, 1973; $\mathrm{H}$ ill and Relf, 1983; Langer and Rodin, 1976; Moore, 1996; Rodin and Langer, 1977). H owever, the conflicting energy levels of the two groups, and the opposing needs for quiet and cleanliness for elderly adults and freedo $m$ to explore and play for children, may result in frustrationsand negative attitudes between the two groups when focused around aplant/ so il based program.

\section{Materials and methods}

This research involved 17 elderly adult clients with varying physical and mental abilities in a university adult day service, and 16 preschool children between 3 and 5 years of age in an adjoining child day care. The number of participants in the program varied daily due to the health of the clients, the turnover rate at the adult day service, and the agreement that the clients should be allowed to exercise autonomy and decide independently if they wish to participate in each activity. These facilities are located in the same campus building, separated only by a small room designed to allow for intergenerational programming.

Theresearch to compare separate age group activities with intergenerational activities consisted of three sessions each week for 10 weeks: one on Mondays for the children's group, a second one on Tuesdays for the elderly adult group, and a third one on Wednesdays which combined both the elderly adults' and children's groups. A similar activity was completed during all three sessions in 1 week, with small modifications to make the activity appropriate for each group. Two volunteers assisted with the children's separate age group activities, two volunteers assisted with the elderly adult separate age group activities, and four volunteersassisted with thecombined group intergenerational activities.

Ten activities ( $T$ able 1 ) were used based on their adaptability and interest for children, elderly adults, and intergenerational participation. Several sources (M oore, 1989; M oore, 1993; N ew York Board of E ducation, 1971; Rothert and Daubert, 1981) were consulted for activity ideas. The selected activities were then designed as projects for the children and elderly adult groups to complete separately as individuals, whiletheintergenerational activity was to be completed as a small group effort to increase social interaction.

The data for each session were collected on video tapes that were analyzed by the researcher after the study wascompleted. Q uantitative data were collected on the attendance and participation of each individual during both separate age group and intergenerational activities, and on the social interactions between elderly adults and preschool children during the intergenerational activities. Participation type was broken down into three levels: " 0 " being present but inactive, "I" being active with direct volunteer assistance, and "II" being independent participation. Participation times were tallied in minutes per session, so the same individual may have received " $O$ ", "I", and/ or "II" for the same activity with varying amounts of time spent in each level of participation. Type of participation percentages were calculated by tallying the total times for each type of participation, then dividing thesenumbers by the total time of the activity. Average participation time was calculated by dividing the total time of the activity by the number of participants.

The video tapes were also used to collect data on social interaction during intergenerational activities. Social interaction scores had four categories: "I" being nonverbal social interaction, "II" being one-directional verbal social interaction (one participant addressed another without getting a response), "III" being two-directional social interaction (conversation), and "IV" being two-directional social interaction and physical cooperation during the activity.

Because of thelimitationsimposed by working with small sample sizes of people (e.g., nonnormality of data), traditional analysis of variance was not appropriate. I nstead, we present group means, report our general observations, and makesuggestions for future program structure.

\section{Results and discussion}

Children's separate age group ACTIVITIES. During children's separate age group activities (Table 1), few " $O$ " scores were observed as inactive children usually left the room where 
the horticulture activity took place. "I" or "II" scores were dependent on the activity and how it was set up. Activities that were difficult or unfamiliar $(\# 1,3,4,5,6,9)$ resulted in high " $\mid$ " ratings as they required the most assistance. Activitiesthat involved familiar tasks, such ascutting, glueing, drawing, or putting soil in pots (\#2, 7, $8,10)$, required little volunteer assistance and resulted in high "II" scores.

Theaverageparticipation timefor children's separate age group activities depended on the set up of the activity. Simple activities that required less direct assistance and allowed the children to work independently (\#2, 7, 8, 10) also encouraged them to work longer. Activities that involved use of fine motor skills $(\# 1,3)$ also required longer time for completion with moderate direct assistance. The assistance required depended on the children's abilities and development of fine motor skills. M ore difficult activities, specifically the ordered step activities (\#4, $5,6,9)$ had low average participation times. These highly structured activities where volunteers worked one-onone with the children resulted in a shorter period of time needed for participants to complete the activity.

The number of participants in children'sseparate age group activities decreased after the first 6 weeks of the study (Table 1). D uring these first 6 weeks, the child day care started the day with a group time where all the participantssat down and talked about theactivities that would take place that day. D uring this group time, the children showed a lot of enthusiasm for the horticulture activities and the participation was never lower than 70\% (average 12.5 individuals). H owever, during the last 4 weeks of the study, the group time was no longer conducted each day. Without an introduction to thehorticulture activities, it became more difficult to encourage children to take part in the horticulture activities which were set up in the room next door. During these last 4 weeks, the number of participants was

T able 1. Comparison of children's participation during separate group (S) and intergenerational (I) H T activities.

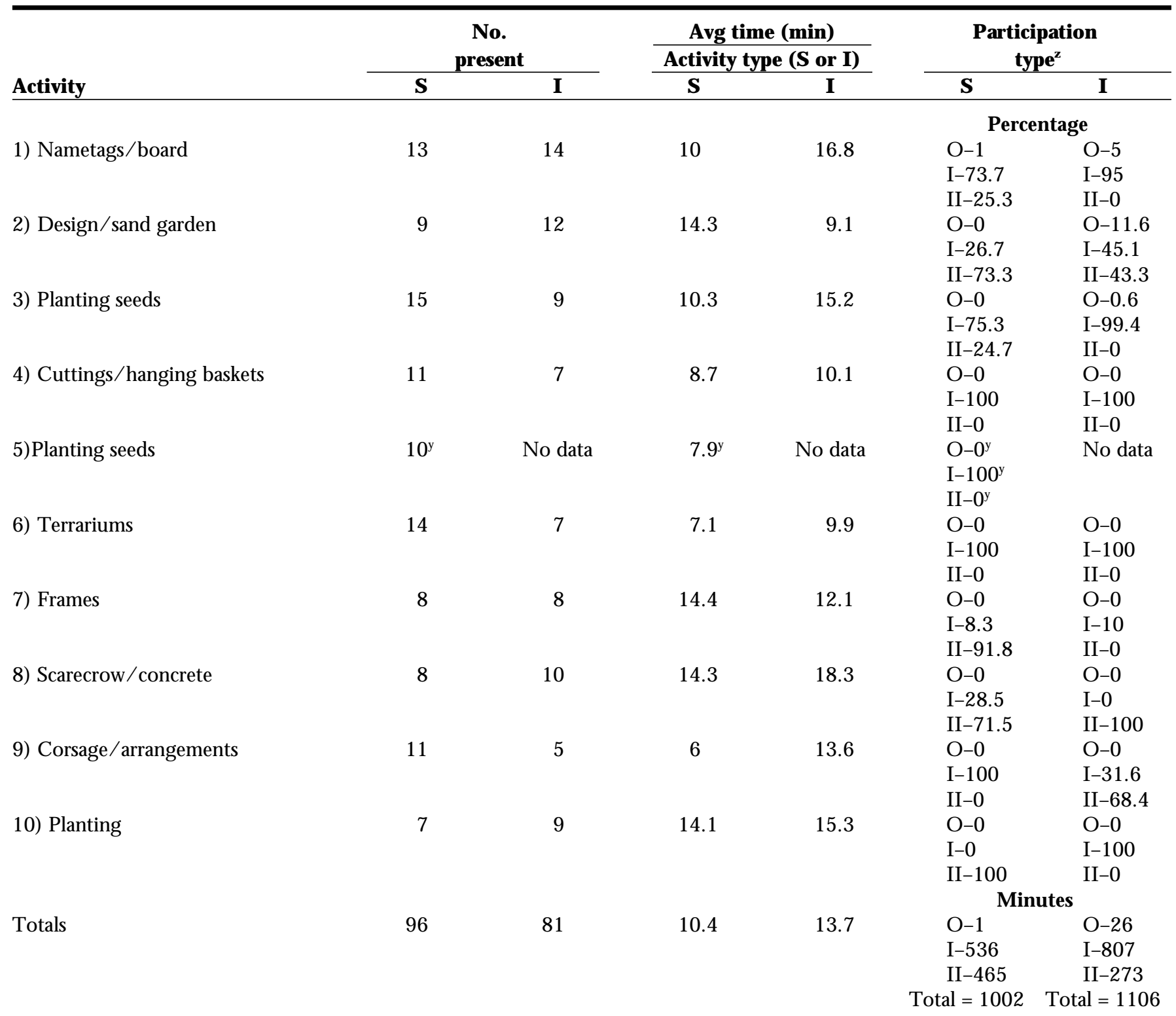


never lower than 50\% (average 8.5 individuals).

Elderly adULts' SEPARATE age GROUP ACTIMTIES. M any of the elderly adult activities (T able2) had " 0 " scores because some participants either could not leave the table without assistance or because they could not work on their own while the volunteer was assisting another participant. "I" and "II" scores were primarily related to theindividuals' physical abilities. The few participants with greater physical skills could work alone after a brief demonstration of the activity and scored primarily "II"s. Individualswho were not ableto work without direct assistance due to physical limitations scored mostly "I"s.
As the elderly adults' participation was less dependent on how the activity was set up and more dependent on each individuals' physical abilities, the activities did not show as much variation in the scores as the children's activities. The average participation time varied with the amount of materials available for the activity. D uring activities with unlimited materials available for each participant (\#1, $2,4,7,8)$ many older adults participated longer. Activities where available materials were limited $(\# 3,5,6$, 10) showed a decreased average time as participants were restricted to the number of products they could complete. The only exception was activity
\#9. $M$ aterials were limited for this activity, but the high difficulty level increased the time spent completing the activity.

INTERGENERATIONAL ACTIVTIES. Participation scores also were used to assess individuals during the intergenerational activities. These data allowed for a comparison of the total participation between separate age group and intergenerational activities to indicate the success of certain activities either in separate age group or combined groups. Individual participation scores showed several changes in participation during the joining of thetwo groups. Thesechangesin scores may have been influenced by a reduc-

Table 2. Comparison of elderly adults' participation during separate group (S) and intergenerational (I) H T activities.

\begin{tabular}{|c|c|c|c|c|c|c|}
\hline \multirow[b]{2}{*}{ Activity } & \multicolumn{2}{|c|}{$\begin{array}{c}\text { No. } \\
\text { present }\end{array}$} & \multicolumn{2}{|c|}{$\frac{\text { Avg time (min) }}{\text { Activity type (S or I) }}$} & \multicolumn{2}{|c|}{$\begin{array}{c}\text { Participation } \\
\text { type }^{z}\end{array}$} \\
\hline & $\mathbf{S}$ & $\mathbf{I}$ & $\mathbf{S}$ & I & $\mathbf{S}$ & I \\
\hline & & & & & \multicolumn{2}{|c|}{ Percentage } \\
\hline 1) N ametags/ board & 9 & 7 & 25.1 & 24.6 & $\begin{array}{l}0-50.4 \\
I-36.3 \\
||-13.1\end{array}$ & $\begin{array}{l}0-70.7 \\
I-16.4 \\
I-12.9\end{array}$ \\
\hline 2) Design/ sand garden & 5 & 7 & 26.2 & 16.1 & $\begin{array}{l}0-37.4 \\
1-57.6 \\
11-5\end{array}$ & $\begin{array}{l}0-75.3 \\
I-10.4 \\
I I-14.3\end{array}$ \\
\hline 3) Planting seeds & 9 & 8 & 19.6 & 17.1 & $\begin{array}{l}0-61.6 \\
1-36.3 \\
11-2.1\end{array}$ & $\begin{array}{l}0-48 \\
1-39.5 \\
11-12.5\end{array}$ \\
\hline 4) Cuttings/ hanging baskets & 7 & 8 & 31.4 & 10.8 & $\begin{array}{l}0-28.9 \\
1-49.3 \\
11-21.9\end{array}$ & $\begin{array}{l}0-70.5 \\
1-17 \\
\mid I-12.5\end{array}$ \\
\hline 5)Planting seeds & $7^{y}$ & No data & $18.3^{y}$ & No data & $\begin{array}{l}0-39.3^{y} \\
1-54.7^{y} \\
11-6^{y}\end{array}$ & No data \\
\hline 6) Terrariums & 8 & 8 & 15.9 & 13.1 & $\begin{array}{l}0-30.2 \\
1-69.8 \\
11-0\end{array}$ & $\begin{array}{l}0-37.1 \\
1-50.4 \\
I I-12.5\end{array}$ \\
\hline 7) Frames & 6 & 10 & 24 & 15.1 & $\begin{array}{l}0-39.3 \\
1-51.9 \\
11-8.8\end{array}$ & $\begin{array}{l}0-61 \\
1-19 \\
11-20\end{array}$ \\
\hline 8) Scarecrow/ concrete & 5 & 3 & 21.6 & 16.7 & $\begin{array}{l}0-24 \\
1-58.4 \\
1 I-17.6\end{array}$ & $\begin{array}{l}0-50.3 \\
I-0 \\
I I-49.7\end{array}$ \\
\hline 9) Corsage/ arrangements & 5 & 7 & 22.2 & 17.3 & $\begin{array}{l}0-49.2 \\
1-50.8 \\
11-0\end{array}$ & $\begin{array}{l}0-46.7 \\
1-21.3 \\
11-32\end{array}$ \\
\hline \multirow[t]{2}{*}{ 10) Planting } & 3 & 7 & 13.7 & 28.4 & $\begin{array}{l}0-38.3 \\
I-61.7 \\
I I-0\end{array}$ & $\begin{array}{l}0-43.6 \\
I-16.9 \\
I I-39.6\end{array}$ \\
\hline & & & & & \multicolumn{2}{|c|}{ M inutes } \\
\hline Totals & 57 & 65 & 22.5 & 17.4 & $\begin{array}{c}0-490 \\
\text { I-677 } \\
\text { II-117 } \\
\text { Total }=1284\end{array}$ & $\begin{array}{c}0-588 \\
I-253 \\
I I-293 \\
\text { Total }=1134\end{array}$ \\
\hline
\end{tabular}

2Participation types: 0 = Present but inactive, I = active with direct volunteer assistance, II = independent participation.

${ }^{\mathrm{y}} \mathrm{N}$ ot included in totals. 
T able 3. T otal cumulative social interaction between elderly adults and preschool children who interacted during intergenerational horticultural therapy activities.

\begin{tabular}{|c|c|c|c|c|c|c|c|}
\hline $\begin{array}{l}\text { Social } \\
\text { interaction } \\
\text { (activity) } \\
\end{array}$ & $\begin{array}{c}\text { I } \\
\begin{array}{c}\text { N onverbal } \\
(\min )\end{array}\end{array}$ & $\begin{array}{c}\text { II } \\
\text { One-direction } \\
\text { verbal } \\
\text { (min) }\end{array}$ & $\begin{array}{c}\text { III } \\
\text { T wo-direction } \\
\text { verbal } \\
\text { (min)0 } \\
\end{array}$ & $\begin{array}{c}\text { IV } \\
\text { T wo-direction } \\
\text { verbal + physical } \\
\text { assistance (min) }\end{array}$ & T otal & $\begin{array}{c}\text { Total time all } \\
\text { participants } \\
\text { (min) }\end{array}$ & $\begin{array}{c}\text { Interaction } \\
\text { time } \\
(\%)\end{array}$ \\
\hline 1) Board & 12 & 8 & 4 & 0 & 24 & 407 & 6 \\
\hline 2) Sand garden & 0 & 15 & 6 & 0 & 21 & 221 & 10 \\
\hline 3) Planting seeds & 0 & 14 & 28 & 0 & 42 & 264 & 15 \\
\hline 4) Cuttings & 2 & 8 & 4 & 8 & 22 & 157 & 14 \\
\hline 5) Planting seeds & No data & No data & No data & N odata & No data & No data & No data \\
\hline 6) Terrariums & 33 & 7 & 0 & 0 & 40 & 174 & 23 \\
\hline 7) Frames & 12 & 2 & 6 & 0 & 20 & 248 & 8 \\
\hline 8) Concrete & 0 & 6 & 0 & 0 & 6 & 233 & 3 \\
\hline 9) Arranging & 24 & 22 & 2 & 2 & 50 & 189 & 26 \\
\hline 10) Planting & 26 & 16 & 8 & 62 & 112 & 337 & 33 \\
\hline
\end{tabular}

tion in individual/ personal assistance available from the volunteers during the activity.

$\mathrm{N}$ o data were collected on week 5 because the video equipment was not properly started during that intergenerational activity. To compensate for this missing intergenerational data the week 5 separate age group activity was not included in comparison data.

Children's intergenerational acTIMTY. Children's participation scores during intergenerational activities (Table1) show an initial higher level of " $O$ " $s$. This is possibly due to the volunteers' inexperience at encouraging participation from all participants, but may also reflect a period of adjustment to thenew situation. These " $O$ " scores disappeared after thevolunteersgained more experience working with their groups and people began to get to know each other. Children's scores also show a higher level of "I"s and lower level of "II" s compared to separate age group activities with only two exceptions (\#8, 9). This may be due to the increased structure of the intergenerational activities. I n order to encourage social interactions between the two groups, activities were designed to promote team work and cooperation between the generations. Independent activity usually decreased social interactions, so participantswere encouraged to work together rather than on their own and activities were redesigned as group participation efforts. The two exceptions $(\# 8,9)$ showed an increase in independent activity because of the simplicity of the activities. These activities were less structured and allowed the participants to work independently but in a group setting.

The children's average participation time (Table 1) increased for all but two intergenerational activities. Because the children were seated at tables and less direct assistance was available, the children required more time to complete the activities in intergenerational groups compared to separate age groups. H owever, fewer children participated in these activities. Several causes could have contributed to the low number of participants. On the days when intergenerational activities took place, the activity started before the scheduled group time on that day and the numbers of participants decreased. These activities also took place in the adult day serviceroom two roomsaway from the child development lab room, making it more difficult to encourage the children to participate. Although it is possible that fewer children chose to participate in these activities because they did not enjoy theintergenerational group, the high number of variables make it difficult to identify the exact reason. Total children's participation comparing separate age group and intergenerational activities are summarized in Table 1.

Elderly adults' inter-generaTIONAL ACTIVITY. The elderly adults' participation scores (Table 2) show a higher level of " 0 " scoresin 8 of the 10 activities compared to separate age group activities, while the other two stayed the same. This was likely due to two separate observed factors. First, in some situations, " $O$ " scores possibly increased because less direct assistance wasavailablefrom thevolunteers. With- out the needed assistance, certain elderly adults who had limited physical abilities or Alzheimer's disease could not participate in the activity. Second, among el derly adultswith higher physical capabilities, the increase in " $O$ " scores may have been because they apparently did not wish to get in the way or prevent the children from participating. $M$ any of these elderly adults who did not need direct assistance to participatesimply sat back and watched the children complete the activity.

Another observed problem that could have affected both the elderly adults with and without physical limitations was excessive direct assistance for the children from the staff or volunteers. D uring the first several activities, many day care staff or volunteers worked closely with the children to keep them involved in the activity, and the adults who needed assistance or encouragement to participate were ignored or given limited access to the activity. Because the children were more vocal with their assistance requests and more willing to leave when they were unsatisfied, the staff and volunteers focused their attention on these children and let the elderly adults remain silent and inactive. With careful coaching and experience in working with both populationsand in meeting their needs more efficiently, the problems of excessive direct assistance for the children decreased, increasing the assistance and attention available for the elderly adults. Throughout the course of the study, the " $O$ " scores decreased. This may be attributed to the assistance of the volunteers who encouraged the elderly adults to work with the children rather than watch, 
and decreased excessive direct assistance for the children. Three of the four early activities ( $\# 1,2,4)$ had over $70 \%$ " 0 " $\mathrm{s}$, while of the last five activities three $(\# 6,9,10)$ showed no more than $47 \%$ " 0 ", with two slightlyhigher scores $(\# 7,8)$ which were a result of the activity set up. During activity \#7, theparticipantsworked independently rather than in groups and social interaction and participation waslow. D uring activity \#8, most elderly adults were unable to reach the wheelbarrow that the children crowded around and therefore watched, instead of participated, in the activity.

The elderly adults' scores also showed an increase in "II" $\mathrm{s}$, possibly due to the limitation on the amount of direct assistance available to them during the activity shared with the children. A link wasobserved between the dilution of available direct assistance and the decrease in "I" scores. As a result, the " $\mathrm{O}$ " and "II" scores probably increased because many of the elderly adults would either not participate or would work on their own. T otal el derly adults' participation comparing separate age group and intergenerational activities is summarized in Table 2.
INTERGENERATIONAL SOCIAL INTERACTIONS. D uring the course of this 10week study, the total percentage of social interaction time between the generations during activities increased over time (Table 3) with two exceptions (\#7, 8). Several factors appear to have contributed to this increase. The two groups becamemore familiar with each other and more comfortable interacting, and the volunteers became more comfortable working with both groups and encouraging participation and social interaction from everyoneat their table. M ost of the inter-generational interaction occurred between the 4 and 5 year old children and the elderly adults with the highest cognitive and physical abilities. This may be becausethe 3 year old children and the elderly adults with Alzheimer's disease or other limited cognitive and physical abilities needed a large amount of direct assistance to complete the activities, and therefore worked with the volunteers more than with the other participants.

Several factors that appeared to reduce the amount of social interaction for all activities were excessive staff or volunteer direct assistance for individuals rather than team or group encouragement, a lack of experience or discomfort in working with either elderly adults or children, or inappropriate activity set up and material distribution. The low social interaction scores of activity \#7 and 8 were probably due to the nature of the activities. D uring activity \#7, participantsworked individually at the sametable. Without a shared product to encourage cooperation very little social interaction took place. D uring activity \#8, the participants stood around a wheelbarrow to mix concrete and functioned as independent workers rather than a team. In addition, many of the elderly adults could not reach the wheelbarrow or chose not to participate in the activity.

of all these activities, the horticulture plant-based activities (\#3, 4, 6, $9,10)$ showed greater percentage of social interaction time than the crafttype activities ( $\# 1,2,7,8)$, (T able 3). Thisindicates that horticulture may be more useful than craft-type activities for intergenerational programs with a goal of increased social interaction and relationship development.

\section{Conclusions}

The HT goals of working with young children or elderly adults have

Table 4. Suggestions for encouraging succesfful social interactions during intergenerational H T activities.

Activities

Set up

Staff/ volunteers

ational interactions
Appeal to both age groups' interest

Be developmentally and functionally appropriate for the groups involved

$U$ se group activities instead of individual activities done in groups

$\mathrm{H}$ ave a definite start and end

$\mathrm{H}$ ave a definite shared goal

Arrange for small groups to allow for easy, more intimate contact

$\mathrm{H}$ ave all participants seated at table, interspersed by age

Introduce participants or have them introduce themselves

$\mathrm{H}$ ave a definite task for each person; emphasize importance of all participation

Encourage one-on-one interaction between participants

Prevent distractions from noise, discomfort, etc.

$\mathrm{H}$ ave a suitable ratio of staff/ volunteers to participants

(Recommended maximum of four participants for one volunteer)

Be familiar with needs of both groups, with appropriate expectations

according to the developmental or functional level of the individuals

A void over-direction or excessive involvement with participants

Direct activity with positive attitude

Encourage interactions among participants

Keep a journal for activity-and self-evaluation

Establish good communication for feedback, input, etc.

D o not force interactions or participation

Are best when either elderly adult or child can assist each other or work together in groups equally Are best for individuals that do not require constant direct assistance from staff/ volunteer 
several similarities, but also several differences. The decrease in children's attendance and elderly adults' participation during intergenerational activities compared to separate age group activities may indicate that introducing intergenerational interactions may detract from the ability to accomplish $H$ T goals associated with actual work with plants. This especially appeared to be the case with theoldest members of the elderly adult group. Participants with more physical limitations or Alzheimer's disease who required a high amount of direct assistance could not participate as long or as much during intergenerational activitieswith limited available assistance and therefore could not gain the direct horticultural benefits.

Because most social interaction was observed between the older children and the elderly adults with more physical and cognitive abilities, this research indicates that the two groups utilized in this study may not be the best combination for intergenerational H T programs. The younger children and elderly adults with limited physical and cognitive abilities who had higher demands for attention from the staff and volunteers appeared to be less strongly or positively influenced by the intergenerational H T programs. Theage and activity level of the participants likely influenced their type of social interaction during inter-generational activities.

The decision to implement intergenerational $\mathrm{H} \mathrm{T}$ programming will depend upon the age, developmental or ability level, and goalsfor theindividuals involved. I ndividualswith high demands for physical assistance during activities may not benefit as much from intergenerational activitiesthat demand high levels of attention and support from volunteers or staff.

H owever, the horticultural plantbased intergenerational activitiesshowed more success than horticultural crafts at encouraging social interactionsbetween thetwo groups. Thecraft-typeactivities involved simple skills such as cutting, glueing, or writing, which encouraged individual activity more than group activity. The horticultural plant-based ac- tivitiesinvolved less individualized tasks and more group effort and team work for completion. For intergenerational programs that aim to increase social interaction and relationship development between generations, horticulture with live plants may help attain these goals more effectively than crafttype activities.

The high level of variables and compounding factors that are introduced when working with young children, elderly adults, staff, and volunteers limits the ability to reach clear conclusions and simply provides direction for conducting programs and future research. Based on this research, Table 4 presents suggestions that should be useful in encouraging successful social interactions during intergenerational $\mathrm{H} \mathrm{T}$ activities.

\section{Literature cited}

Abbott, G., V. Cochran, and A.A. Clair. 1997. Innovation sin intergenerational programsfor persons who areelderly: Therole of horticultural therapy in a multidisciplinary approach, p. 27-38. In: S.E. Wells (ed.). H orticultural therapy and theolder adult population. $\mathrm{H}$ aworth Press, Binghamton, N.Y.

Aday, R.H., C.R. Sims, and E. Evans. 1991. Youth's attitudes toward the elderly: The impact of intergenerational partners. J. A ppl. Gerontol. 10(3):372-384.

Bunn, D.E. 1986. Group cohesiveness is enhanced aschildren engagein plant stimulated discovery activities. J. Therap. $\mathrm{H}$ ort. 1:37-43.

Chapman, N .J . and M .B. N eal. 1990. The effects of intergenerational experiences on adolescents and older adults. The Gerontol. 30(6):825-832 .

D ellman-J enkins, M ., D . L ambert, and D. Fruit. 1991. Fostering preschoolers' prosocial behaviorstoward theelderly: The effect of an intergenerational program. Educ. Gerontol. 17:21-32.

Epstein, S.G . and D.S. Greenberger. 1990. Nurturing plants, children, and older individuals: Intergenerational horticultural therapy. J. Therap. H ort. 5:16-19.

Green, K. 1994. Encouraging nurturing behavior of two to seven year olds by introducing plants and flowers, p. 395408. In: J. Flagler and R.P. Poincelot (eds.). People-plant relations: Setting research priorities, A national symposium. $\mathrm{H}$ aworth Press, Binghamton, N.Y.

$H$ aas, K., S.P. Simson, and N .C. Stevenson. 1998. Older persons and horticultural therapy practice, p. 231-255. In: S.P. Simson and M.C. Straus (eds.). H orticulture as therapy: Principles and practice. $\mathrm{H}$ aworth Press, Binghamton, N.Y.

H efley, P.D. 1973. H orticulture-A therapeutic tool. J. Rehab. 39(1):27-29.

H ill, C.O . and P.D. Relf. 1983. Gardening as an outdoor activity in geriatric institutions. Activities, Adapt. Aging 3(1):4754.

Kerrigan, J. and N.C. Stevenson. 1997. Behavioral study of youth and elders in an intergenerational horticultural therapy program, p. 141-154. In: S.E. Wells (ed.). $\mathrm{H}$ orticultural therapy and the older adult population. $\mathrm{H}$ aworth Press, Binghamton, N.Y.

Langer, E.J. and J. Rodin. 1976. The effects of choice and enhanced personal responsibility for the aged: A field experiment in an institutional setting. J. Personality Social Psychol. 34(2):191-198.

M oore, B. 1989. Growing with gardening. U niv. N.C. Press, Chapel H ill.

M oore, R.C. 1993. Plants for play. M IG Communications, Berkeley, Calif.

M oore, R.C. 1996. Compact nature: The role of playing and learning gardens on children's lives. J. Therap. H ort. 8:72-82.

$\mathrm{N}$ ew York B oard of E ducation. 1971. Gardening science manual. $\mathrm{N}$ ew York Board of Education publication, $\mathrm{N}$ ew York.

Rodin, J. and E.J. Langer. 1977. Longterm effects of a control-relevant intervention with the institutionalized aged. J. Personality Social Psychol. 35(12):897902.

Rothert, E.R. and J.R. Daubert. 1981. $\mathrm{H}$ orticultural therapy for nursing homes, senior centers, retirement living. Chicago $\mathrm{H}$ ort. Soc., Chicago.

Seefeldt, C. 1987. Intergenerational programs. Childhood Educ. (O ctober):1418.

Seefeldt, C. 1989. Intergenerational programs: Impact on attitudes. J. Children Contemp. Soc. 20:185-194.

Tice, C.H. 1985. Perspectives on intergenerational initiatives: Past, present, and future. Children Today 14(5):6-11. 